\title{
Mortality in Patients with Multiple Sclerosis
} Multipl Skleroz Hastalarında Mortalite

\author{
(1) Sümeyra Şamli1 , (1) Murat Kürtüncü 2 \\ 1 Vienna University Faculty of Medicine, Department of Neurology, Vienna, Austria \\ 2Istanbul University Istanbul Faculty of Medicine, Department of Neurology, Istanbul, Turkey
}

Keywords: Multiple sclerosis, mortality, Sweden, research

Anahtar Kelimeler: Multipl skleroz, mortalite, İsveç, araştırma

\section{Mortality in Patients with Multiple Sclerosis}

Studies on life expectancy of patients with multiple sclerosis (MS) show increased mortality rates. Cardiovascular diseases, infections, and falls are among the most common causes of death, although the cause of death may vary depending on the pattern of disease involvement and other accompanying diseases. Among infections, aspiration pneumonia and sepsis caused by dysphagia are the leading causes of death.

Burkill et al. (1) investigated cause-specific mortality in MS in Sweden. Using the Multiple Sclerosis Register and the Causes of Death Register, the researchers monitored patients diagnosed between 1968 and 2012 until 2013 or until their death and compared the survival data of nearly thirty thousand patients with MS with individuals without MS. During this comparison, sex, year of birth, vital status, and region of residence at the time of MS diagnosis were also taken into consideration. Interestingly, the age and sex criteria stood out. In the study, the causes of death were categorized into 6 groups, as cardiovascular, respiratory tract diseases, other non-respiratory infectious diseases, suicide, accidents, and MS. The mortality rates of patients with MS and the general population were compared using Cox proportional hazard models.

Sixty-six percent of the study population consisted of women. Thirty-two percent of patients with MS and $20 \%$ of the general population died. Although there was no significant difference between the cohorts in terms of sex, year of birth, region of residence, and educational status, the researchers found a hazard ratio (HR) of 2.9 for patients with MS for all-cause mortality.

It is noteworthy that the most prominent risk increases among the causes of death in MS patients were from respiratory (HR: 5.1) and infectious (HR: 4.1) diseases. In terms of infections, the second important reason for the increase in mortality was sepsis (HR: 4.8).

As expected, the rate of mortality varied according to the age at which the patients were diagnosed. Patients with MS diagnosed under the age of 40 years had a higher mortality rate than older age groups. The HR was 10.2 under the age of 18 years, whereas this ratio was 4.9 in patients with MS aged 18-40 years.

In this study, mortality rates of MS patients in all age groups were significantly higher than the general population, as was observed in studies investigating the mortality rate in MS patients. As expected, when compared with the general population, the study showed that respiratory problems and infectious diseases were the most important risk factors in patients with MS. The risk of death for patients diagnosed as having MS at an early age was higher than that of patients diagnosed at a later age was another striking finding. This age-related decrease in proportional risk may be attributed to advanced diagnostic methods, treatments applied in early stages of the disease, and the effective treatment of MS and comorbid diseases such as infection. Apart from respiratory tract infections, it is also interesting that the most common infection was sepsis in both the MS group and the general population. In addition, it

Address for Correspondence/Yazışma Adresi: Sümeyra Şamlı MD, Vienna University Faculty of Medicine, Department of Neurology, Vienna, Austria Phone: +90 5364944516 E-mail: sumeirasamli@gmail.com ORCID ID: orcid.org/0000-0002-2210-6530

Received/Geliş Tarihi: 25.09.2017 Accepted/Kabul Tarihi: 01.10.2017

${ }^{\oplus}$ Copyright 2018 by Turkish Neurological Society

Turkish Journal of Neurology published by Galenos Publishing House. 
is noteworthy that the risk of acquired cardiovascular diseases in patients with MS was more than twice as high in the study than in previous studies.

This study presents important results as it covers a 45 -year time frame and many patients. Being the first comprehensive mortality study and also investigating the causes of death also increase the significance of the study. There is a need for studies that examine whether the high mortality risk observed in patients with MS differs between countries.

\section{Reference}

1. Burkill S, Montgomery S, Hajiebrahimi M, Hillert J, Olsson T, Bahmanyar S. Mortality trends for multiple sclerosis patients in Sweden from 1968 to 2012. Neurology 2017;89:555-562. 